\title{
Vulvar precedence of intestinal anses: a rare complication of uterine rupture
}

Keywords: vulvar procidence, intestinal anses, uterine rupture, placental retention, hemorrhagic shock

\section{Clinical Images}

It is a 20year old paucipar, received in our structure after delivery in a health post, for placental retention, vulvar externalization of intestinal loops. Childbirth was performed by low voice one hour before with birth of a macrosome $(4000 \mathrm{~g})$, fresh stillborn. There was dystocia of the shoulders to expulsion, managed by uterine expressions. There was no history of Caesarean section. On arrival, there was a state of hemorrhagic shock. The gynecological examination found vulvar bleeding, a uterus at the level of the umbilicus, a procidence of maternal intestinal loops through the vulva. The biological assessment found a hemoglobin level at 7.5g/dl, GB 9.103/ul, platelets at 42.103/ $\mathrm{ul}$, serum creatinine at $16.78 \mathrm{mg} / 1$.

Emergency laparotomy revealed a left uterine rupture extending up to the left appendix, where the slender loops entered the vagina with an externalized necrotic portion (Figure 1). The placenta sat in the abdomen. Gestures: hysterectomy of interannexal haemostasis and intestinal resection of $30 \mathrm{~cm}$ with ileo-ileal anastomosis.

The patient had been resuscitated post-operatively for 8 days. She had received 7 iso-rhesus iso-group blood bags. She was out at J13 postoperatively.

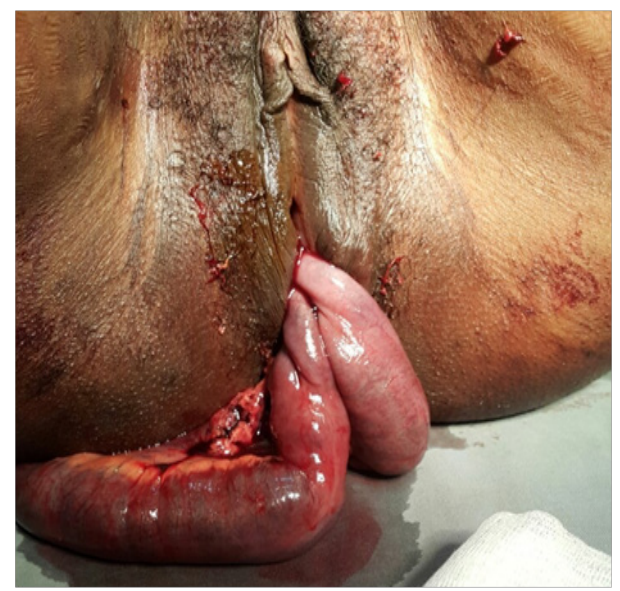

Figure I Vulvar Procidence of Intestinal Anses.

\author{
Volume 4 Issue I - 2018
}

Thiam M, ${ }^{1,2}$ Gueye I, ${ }^{1,2}$ Dieme Mef, ${ }^{3,4}$ Niang MM, ${ }^{3,4}$ Diouf AA, ${ }^{3,4}$ Ba PA, ${ }^{1,5}$ Gassama O,,5 Cisse $M L^{1,2}$

'Department of Health Sciences, University of Thiès, Senegal ${ }^{2}$ Department of Obstetrics and Gynecology, Thies Regional Hospital, Senegal

${ }^{3}$ Gynecological and Obstetrical Clinic, The Dantec University Teaching Hospital of Dakar, Senegal ${ }^{4}$ Cheikh Anta Diop University of Dakar, Senegal

${ }^{5}$ Department of Surgery and Specialties, Thies Regional Hospital, Senegal

Correspondence: Mariétou Thiam, Assistant Professor at faculty of Health sciences, University of THIES, Obstetrician and Gynecologist at the THIES Regional Hospital, Senegal, Email maricoulibaly 10@gmail.com

Received: February 07, 2018 | Published: February 12, 2018

\section{Acknowledgements}

The corresponding author is the guarantor of submission.

\section{Conflict of interest}

Authors declare that there is no conflict of interest. 